\title{
Mass Transfer in Steelmaking Operations
}

\author{
Roberto Parreiras Tavares \\ Federal University of Minas Gerais \\ Brazil
}

\section{Introduction}

The productivity of steelmaking processes, including production and refining of liquid steel, depends on the mass transfer rates. Due to the high temperatures involved in the processing of liquid steel, the rate controlling step of the processes is usually a mass transfer step.

In steelmaking operations, different situations of mass transfer can occur, depending on the phases involved,

- liquid-liquid mass transfer, in the case of reactions involving liquid steel and slag;

- liquid-gas mass transfer, when a gas is injected into or onto liquid steel;

- liquid-solid mass transfer, when solid particles are injected into liquid steel to promote refining reactions.

In all these situations, the evaluation of the mass transfer coefficient and the identification of the factors that affect its value are very important tasks. Different techniques have been developed to evaluate the mass transfer coefficient. These techniques vary according to the phases involved in the system being analysed.

In the present chapter, the mass transfer coefficients will be defined. Then, the different techniques that have been adopted to evaluate the mass transfer coefficient will be presented and briefly discussed. Finally, a case study, analysing the mass transfer rate during decarburization in the RH degasser, will be described and discussed.

\section{Mass transfer coefficient}

\subsection{Definition}

The mass transfer rate of a certain component A between two phases can be expressed by the following relationship

$$
\mathrm{j}_{\mathrm{A}}=-\left.\mathrm{D}_{\mathrm{A}} \cdot \frac{\partial \mathrm{C}_{\mathrm{A}}}{\partial \mathrm{x}}\right|_{\mathrm{x}=0} \cdot S
$$

where

$\mathrm{j}_{\mathrm{A}}=$ mass transfer rate of component $\mathrm{A}(\mathrm{kg} / \mathrm{s})$;

$\mathrm{S}=$ interface area $\left(\mathrm{m}^{2}\right)$;

$\mathrm{D}_{\mathrm{A}}=$ diffusion coefficient of component $\mathrm{A}$ in a certain phase $\left(\mathrm{m}^{2} / \mathrm{s}\right)$;

$\left.\frac{\partial \mathrm{C}_{\mathrm{A}}}{\partial \mathrm{x}}\right|_{\mathrm{x}=0}=$ concentration gradient of component $\mathrm{A}$ at the interface between the two phases $\left(\mathrm{kg} / \mathrm{m}^{4}\right)$ 
In equation (1), the mass transfer rate is defined only in terms of diffusion. At the interface between two fluid phases, there is also an additional contribution to the mass transfer rate due to bulk flow.

The application of equation (1) in the evaluation of mass transfer rates presents some difficulties. It is then usually necessary to resort to experimental data to determine the mass transfer rate. To obtain experimental data, a mass transfer coefficient, defined by equation (2), is normally used.

$$
\begin{gathered}
\mathrm{j}_{\mathrm{A}}=\mathrm{k} \cdot \mathrm{S} \cdot\left(\mathrm{C}_{\mathrm{A}}^{\mathrm{o}}-\mathrm{C}_{\mathrm{A}}^{\mathrm{s}}\right) \\
\mathrm{k}=\frac{-\left.\mathrm{D}_{\mathrm{A}} \cdot \frac{\partial \mathrm{C}_{\mathrm{A}}}{\partial \mathrm{x}}\right|_{\mathrm{x}=0}}{\left(\mathrm{C}_{\mathrm{A}}^{\mathrm{o}}-\mathrm{C}_{\mathrm{A}}^{\mathrm{s}}\right)}
\end{gathered}
$$

Combining equations (1) and (2), an expression for the mass transfer coefficient can be obtained.

It is also useful to define a volumetric mass transfer coefficient, which is the product of the mass transfer coefficient and the interface area.

$$
\mathrm{k}_{\mathrm{V}}=\mathrm{k} . \mathrm{S}
$$

where $\mathrm{k}_{\mathrm{V}}$ is the volumetric mass transfer coefficient $\left(\mathrm{m}^{3} / \mathrm{s}\right)$.

In steelmaking systems, when there is chemical reaction and component $\mathrm{A}$ is transferred from one phase to the other, the concentration of $\mathrm{A}$ at the interface is close to the equilibrium concentration, since the mass transfer is usually the rate controlling step in these situations.

\subsection{Evaluation}

The value of the mass transfer coefficient can be deduced based on first principles. In this case, it is necessary to model the flow of the phases and to determine the concentration gradient at the interface. Then, equation (3) is applied and the mass transfer coefficient is determined. The values of the mass transfer coefficient are then expressed in terms of correlations involving dimensionless numbers (Sherwood, Reynolds, Grashof and Schmidt). This method is normally applied to simple situations, usually in one dimensional flow. In more complex situations, this method can also be adopted but it will be necessary to solve the Navier-Stokes equations (laminar or turbulent form, according to the kind of flow) and the mass conservation equations for the species involved.

In steelmaking processes, the mass transfer coefficient is usually estimated based on experimental results. Due to the costs and difficulties associated to experiments with liquid steel, physical modelling of the industrial processes, using water to simulate liquid steel, is usually adopted to investigate mass transfer rates.

Recently, Singh et al (2009) investigated mass transfer between slag and metal in a physical model of a BOF converter. Different oils were used to simulate liquid slag. To evaluate the mass transfer rate, the distribution coefficient of benzoic acid between water and oil was determined. Assuming that the mass transfer rate between the two fluids owing to mixing of the phases was of first order, the authors estimated the mass transfer rate constant, which is related to the mass transfer coefficient. 
Wei et al (2007) used the dissolution of sodium chloride powder to determine the mass transfer coefficient in a physical model of a RH degasser.

A different approach was adopted by Sakaguchi \& Ito (1995) to analyse the mass transfer process in gas stirred vessels under reduced pressure. In this investigation, the desorption of $\mathrm{CO}_{2}$ from aqueous solutions was used to deduce the volumetric mass transfer coefficient, assuming that the process is controlled by mass transfer. A similar technique was used by Maruoka et al (2010) to investigate the effect of the bottom bubbling condition on surface reaction on an oxygen-water system, simulating refining of steel in a ladle. In this case, the desorption of oxygen was monitored during the experiments.

In industrial systems, the mass transfer coefficient is usually obtained by curve fitting to experimental data. A mathematical model, based on mass transfer control, is proposed. Variations of concentration of a certain component as a function of time are predicted and compared to experimental data. A mass transfer coefficient that leads to the best agreement between experimental data and theoretical predictions is then determined (Kitamura et al, 2009; Hamano et al, 2004).

In the next section, a case study, analysing mass transfer rate during decarburization in the $\mathrm{RH}$ degasser will be presented and discussed.

\section{Case study: decarburization in the $\mathrm{RH}$ degasser}

\subsection{Introduction}

The $\mathrm{RH}$ process is a secondary refining process that can simultaneously attain significant levels of removal of interstitial elements, such as nitrogen, hydrogen and carbon elements, from liquid steel.

In this process, the melt circulation and the decarburization rates play a very significant role in determining the productivity of the equipment. In previous investigations, the melt circulation rate in the RH process has been evaluated by means of mathematical modeling (Park et al, 2001; Park et al, 2000), physical modeling (Kamata et al, 1998; Seshadri \& Costa, 1986; Nakanishi et al, 1975) and also using data obtained in industrial plants (Kondo et al, 1989; Kuwabara et al, 1988). The effects of different parameters, such as argon flow rate, snorkels diameters, pressure in the vacuum chamber and position of the argon injection points, on the melt circulation rate have been analyzed in these investigations.

The decarburization rate in the RH process has also been studied using data from plant trials (Inoue et al, 1992; Yamaguchi et al, 1992; Kishimoto et al, 1993; Takahashi et al, 1995), lab scale experiments (Inoue et al, 1992; Kishimoto et al, 1993) and water models (Inoue et al, 1992; Seshadri et al, 2006). Mathematical models have been proposed to evaluate the decarburization kinetics. The roles of the different reaction sites, interfaces between molten steel and argon bubbles injected into the snorkel, free surface of the molten steel in the vacuum chamber and bubbles of carbon monoxide, have been analyzed (Takahashi et al, 1995). It is general agreement that, at low carbon concentrations, the decarburization rate is controlled by the carbon mass transfer, and that a first-order equation can describe the decarburization kinetics (Inoue et al, 1992; Yamaguchi et al, 1992; Takahashi et al, 1995).

In this case study, the melt circulation rate and the decarburization reaction in the $\mathrm{RH}$ process have been studied by means of physical modeling. The effects of the gas flow rate and of the diameter of the nozzles used in the gas injection have been analyzed. The decarburization reaction of liquid steel was simulated using a reaction of $\mathrm{CO}_{2}$ desorption from caustic solutions (Guo \& Irons, 1998). 


\subsection{Methodology}

The experiments with the physical model were divided in two parts, one to evaluate the melt circulation rate and the other to determine the decarburization rate. These experiments are described below, after a description of the physical model and of the experimental set-up.

\subsubsection{Experimental set-up}

A schematic view of the physical model of the RH degasser is depicted in Fig. 1.

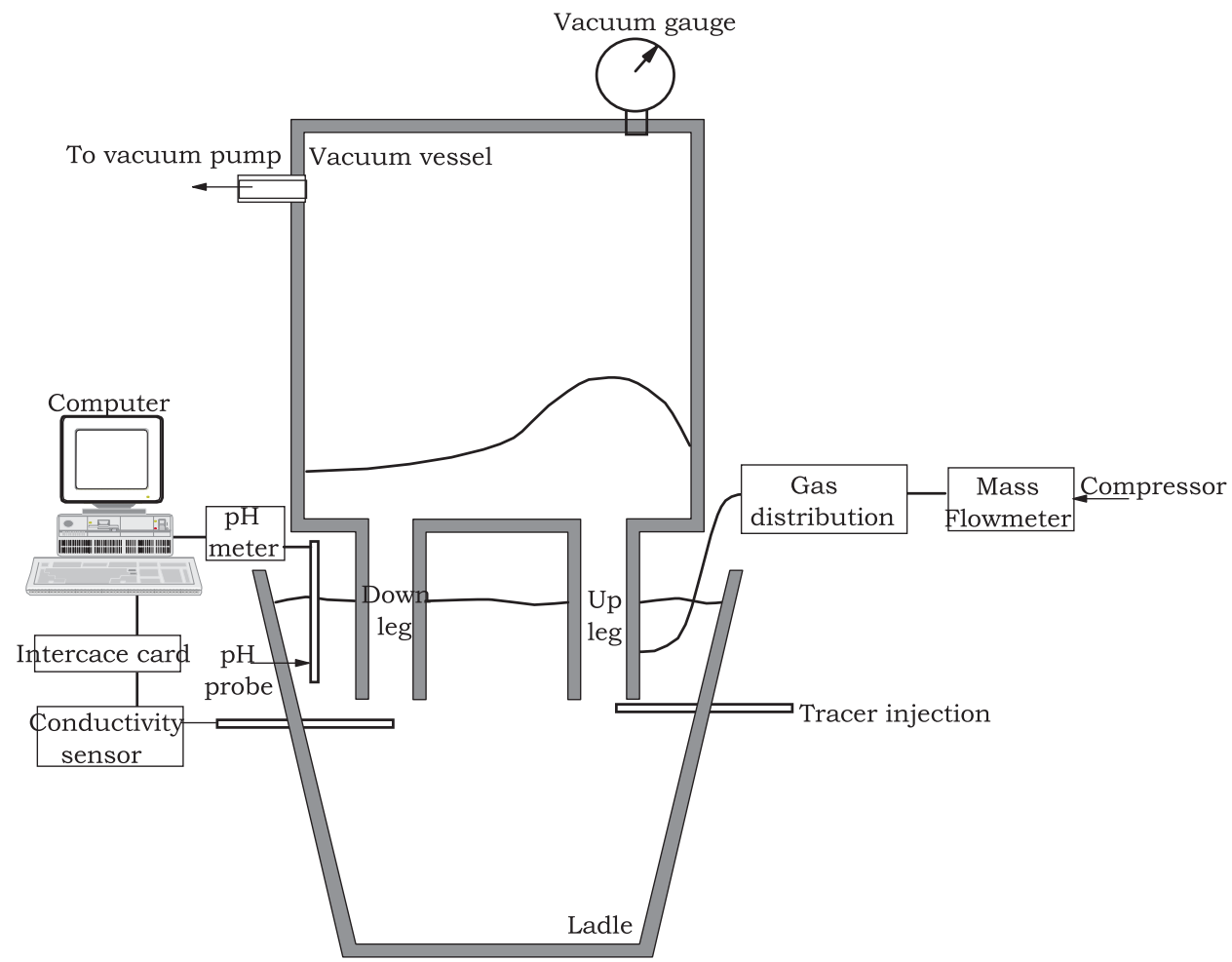

Fig. 1. Schematic view of the experimental set-up

Table 1 presents the dimensions of the physical model and the main characteristics of the gas injection system. These dimensions correspond to a 1:5 scale of an industrial RH degasser.

During the experiments, air supplied by a compressor was injected in the upleg snorkel. The flowrate was measured by a mass flowmeter and controlled manually. There were no individual measurements of flowrate for each injection nozzle. To equally distribute the gas flow rate among the nozzles, the air was first injected in the central region of a small chamber. This chamber was connected to each nozzle using pipes with the same length and diameter.

The pressure in the vacuum chamber was controlled by a system of valves and monitored by a pressure gauge.

The levels of water in the ladle and in the vacuum chamber were controlled and kept constant in all the experiments. 


\begin{tabular}{|c|c|}
\hline Parameters & Value \\
\hline $\begin{array}{ll}- & \text { upper diameter }(\mathrm{m}) \\
- & \text { lower diameter }(\mathrm{m}) \\
- & \text { height }(\mathrm{m}) \\
- & \text { liquid level }(\mathrm{m})\end{array}$ & $\begin{array}{l}0.720 \\
0.648 \\
0.750 \\
0.655\end{array}$ \\
\hline $\begin{array}{ll} & \\
\text { - } & \text { diameter }(\mathrm{m}) \\
- & \text { height }(\mathrm{m}) \\
- & \text { liquid level }(\mathrm{m}) \\
- & \text { pressure }(\mathrm{Pa} \text { - gauge })\end{array}$ & $\begin{array}{c}0.415 \\
0.700 \\
0.090 \\
-2700\end{array}$ \\
\hline $\begin{array}{ll} & \\
\text { - } & \text { length }(\mathrm{m}): \\
- & \text { diameter }(\mathrm{m}) \\
- & \text { depth of immersion }(\mathrm{m}) \\
- & \text { distance between centers }(\mathrm{m})\end{array}$ & $\begin{array}{l}0.312 \\
0.120 \\
0.120 \\
0.300\end{array}$ \\
\hline $\begin{array}{ll}\text { Gas injection: } \\
- & \text { flowrate (STP } 1 / \mathrm{min}) \\
- & \text { nozzles: } \\
- & \text { number } \\
- & \text { diameters }(\mathrm{mm}) \\
- & \text { position (below liquid level) }(\mathrm{m})\end{array}$ & $\begin{array}{l}50-500 \\
\\
10 \\
1.0,1.5,2.8 \\
\quad 0.04\end{array}$ \\
\hline
\end{tabular}

Table 1. Characteristics of the RH physical model

\subsubsection{Melt circulation rate}

To determine the melt circulation rate, the method used by Seshadri et al (2006) was adopted. In this procedure, a solution of potassium chloride is injected in the upleg snorkel in the form of a pulse. The concentration of $\mathrm{KCl}$ in the downleg snorkel is then continuously monitored. Since the electrical conductivity of water is affected by the presence of $\mathrm{KCl}$, its concentration was calculated based on the signal generated by the electrical conductivity sensor, using a calibration curve previously determined.

Fig. 2 illustrates typical curves representing the variation of concentration of $\mathrm{KCl}$ in the downleg snorkel as a function of time. The circulation rate was estimated using the following equation

$$
\Gamma=\frac{\mathrm{V}}{\mathrm{A} / \Delta \mathrm{C}} \rho
$$

where

$\Gamma$ is the circulation rate $(\mathrm{kg} / \mathrm{s})$;

$\mathrm{V}$ is the volume of water in ladle $\left(\mathrm{m}^{3}\right)$,

$\mathrm{A}$ is the area under the curve during the first peak (kg.s/m³) (see Fig. 2),

$\Delta \mathrm{C}$ is the variation of concentration of $\mathrm{KCl}$ at the end of the experiment $\left(\mathrm{kg} / \mathrm{m}^{3}\right)$, $\rho$ is the density of the circulating fluid $\left(\mathrm{kg} / \mathrm{m}^{3}\right)$. 


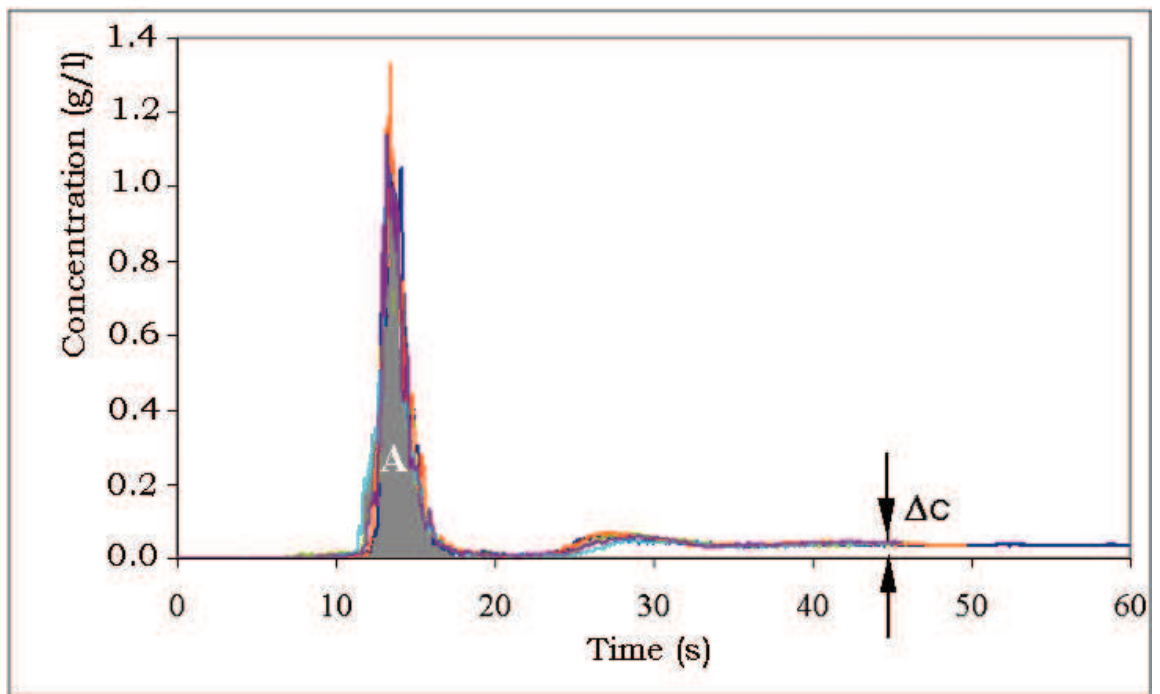

Fig. 2. Typical curves obtained in the experiments to evaluate the melt circulation rate

To guarantee the reliability of the experiments, the mass balance of $\mathrm{KCl}$ was verified in all the tests. Ten experiments were carried for each experimental condition.

\subsubsection{Decarburization rate}

The desorption of $\mathrm{CO}_{2}$ from caustic solutions was used to simulate the decarburization reaction of liquid steel (Guo \& Irons, 1998). In these experiments, $\mathrm{CO}_{2}$ was injected into an aqueous solution of sodium hydroxide $(\mathrm{NaOH})$ with a concentration of 0.01 g.mol/l, until the $\mathrm{pH}$ reached a preset value (approximately 6.5). At this point, the operation of the $\mathrm{RH}$ physical model was started, with the injection of air at the upleg snorkel. This injection leads to $\mathrm{CO}_{2}$ desorption and to an increase in the $\mathrm{pH}$ of the circulating fluid. The variation of the $\mathrm{pH}$ was monitored during the entire test at a frequency of $0.33 \mathrm{~Hz}$. A calibration curve was used to convert $\mathrm{pH}$ values into aqueous $\mathrm{CO}_{2}$ concentration. Different locations for the $\mathrm{pH}$ sensor were adopted, without significant differences in the results. Air flowrates, ranging from 50 to 500 STP $1 / \mathrm{min}$, were used in the tests. Nozzles with diameters of 1.0, 1.5, 2.2 and $2.8 \mathrm{~mm}$ were also tested in the simulations. The remaining conditions were kept constant in all the experiments. Three experiments were run for each experimental condition. Fig. 3 shows a typical variation of aqueous $\mathrm{CO}_{2}$ concentration during a test to evaluate the decarburization rate.

\subsection{Results and discussion}

\subsubsection{Melt circulation rate}

The variation of the melt circulation rate as a function of the gas flow rate for the different diameters of the injection nozzles is presented in Fig. 4. For a given diameter of the nozzle, the circulation rate tends to increase when the gas flow rate increases. Above a certain flow rate, the circulation rate remains approximately constant or shows a slight tendency of reduction. This kind of behavior has also been determined in other works (Park et al, 2001; Seshadri \& Costa, 1986; Seshadri et al, 2006). 


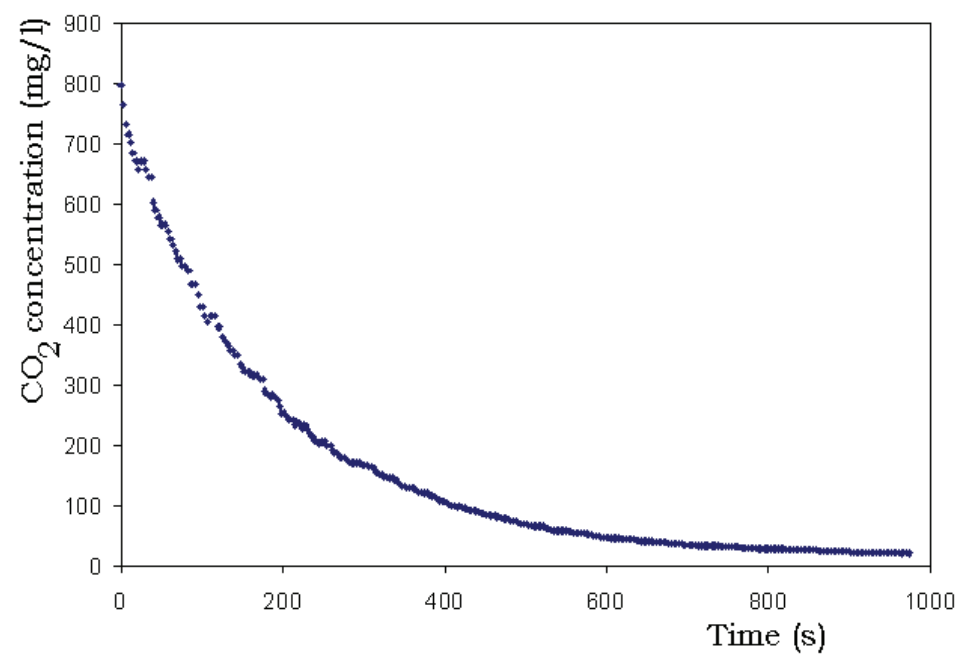

Fig. 3. Typical variation of aqueous $\mathrm{CO}_{2}$ concentration as a function of time during a test An increase in the diameter of the injection nozzles leads to higher circulation rates. According to Park et al (2001), this effect can be analysed considering the variation of the plume area in the upleg snorkel. To confirm that, during the experiments, images of the cross section of the upleg snorkel were obtained using a video camera. These images were post processed to identify the area occupied by the plume. Fig. 5 illustrates the original and the post processed images taken from the upleg snorkel. In Fig. 5, the black area represents the plume.

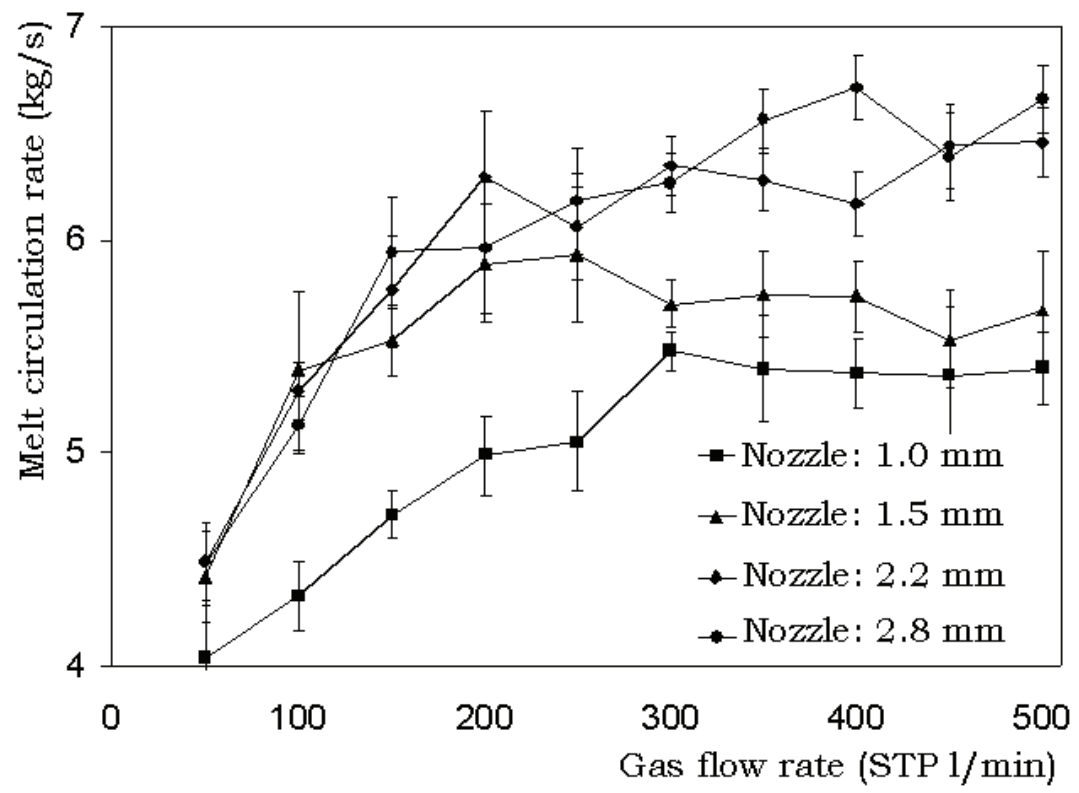

Fig. 4. Variation of the melt circulation rate with gas flow rate for different nozzles diameters 

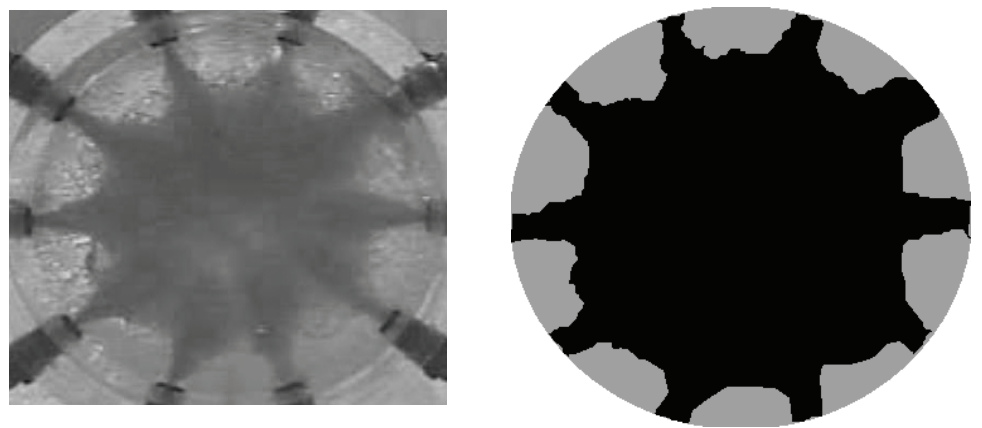

Nozzle: $1.0 \mathrm{~mm}$
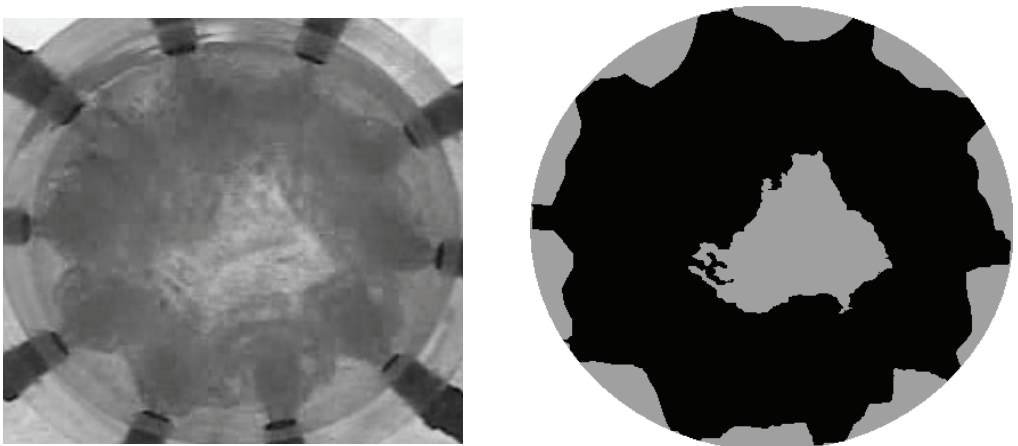

Nozzle: $2.8 \mathrm{~mm}$

a)

b)

Fig. 5. a) Image taken from the cross section of the upleg snorkel. b) Post processed image identifying the plume

Fig. 6 presents the results of circulation rate and the percentage of the area of the upleg snorkel that is occupied by the plume, for the experiments with nozzles of 1.5 and $2.8 \mathrm{~mm}$ in diameter. Similar trend was observed for the other nozzles. Based on these results, it is possible to analyze the variation of the circulation rate in terms of the variation of the plume area in the upleg snorkel. This supports the theoretical analysis carried out by Park et al (2001). Fig. 7 presents a graph of the circulation rate as a function of the plume area, showing a linear relationship between these two variables, within the conditions tested in the present work.

In an attempt to generalize the results for the circulation rate, a dimensionless circulation rate was defined as:

$$
\text { Dimensionless Circulation Rate }=\frac{V_{\mathrm{ds}}^{2}}{\text { g.d }_{\mathrm{o}}}
$$

where

$\mathrm{V}_{\mathrm{ds}}$ is the velocity of the fluid in the downleg snorkel (m/s),

$\mathrm{g}$ is the acceleration due to gravity $\left(\mathrm{m} / \mathrm{s}^{2}\right)$,

$\mathrm{d}_{\mathrm{o}}$ is the diameter of the nozzle $(\mathrm{m})$. 


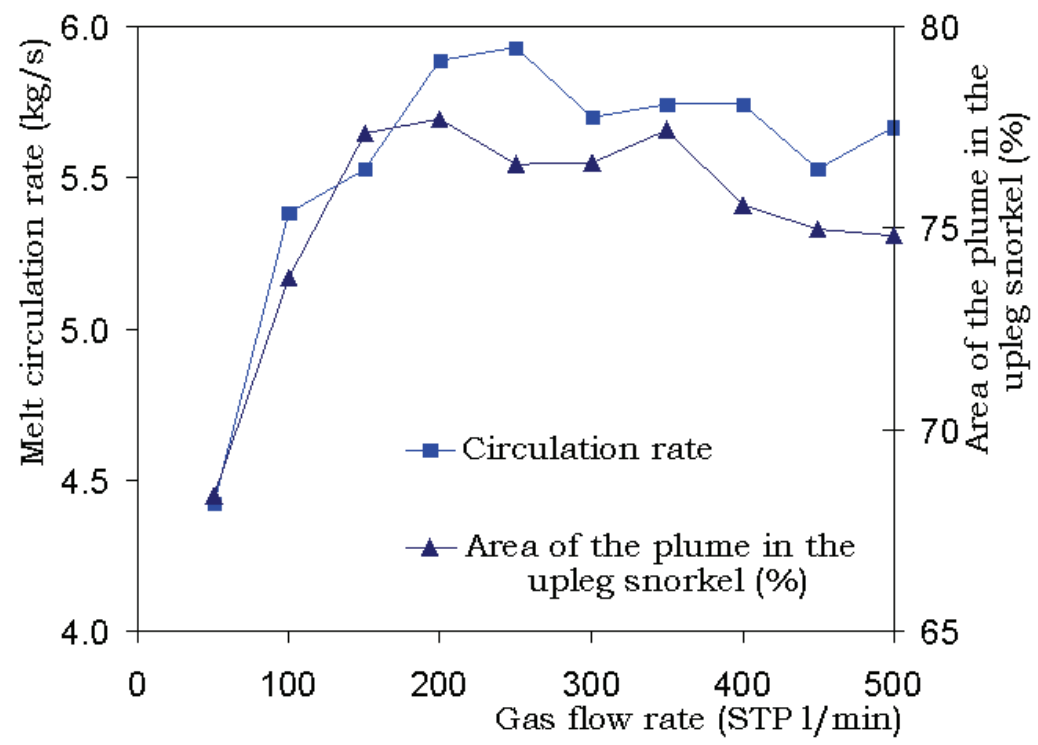

Nozzle: $1.5 \mathrm{~mm}$

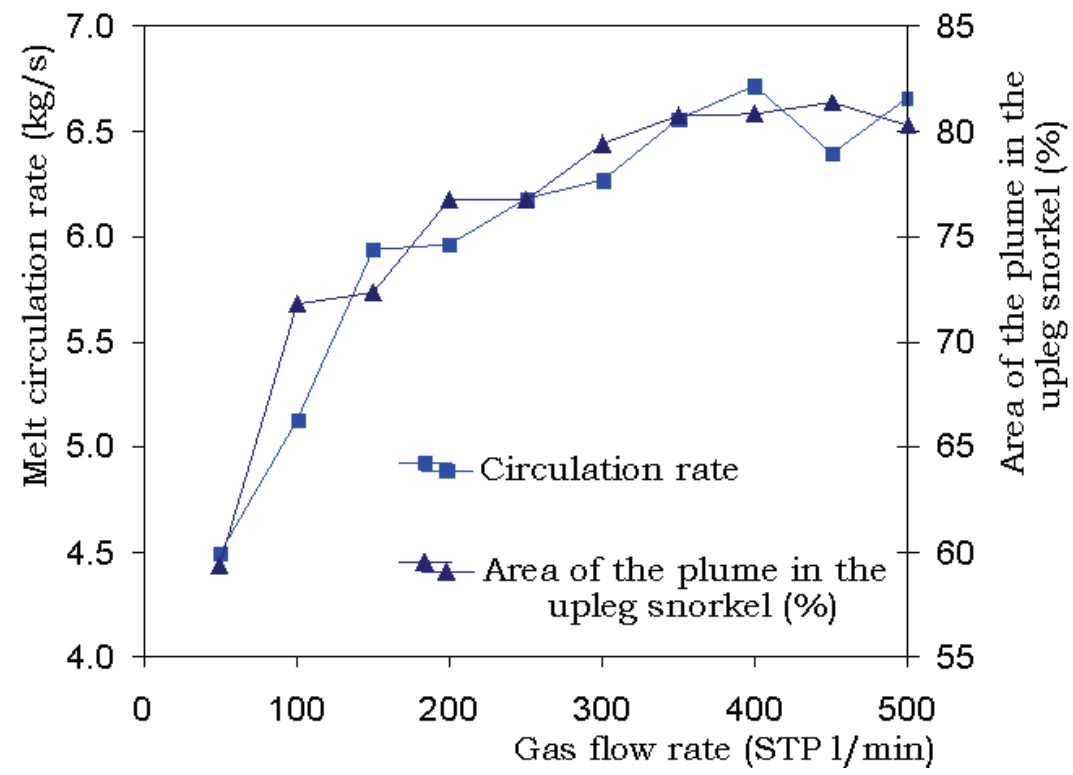

Nozzle: $2.8 \mathrm{~mm}$

Fig. 6. Circulation rate and area of the plume in the upleg snorkel as a function of gas flow rate for two different nozzle diameters 


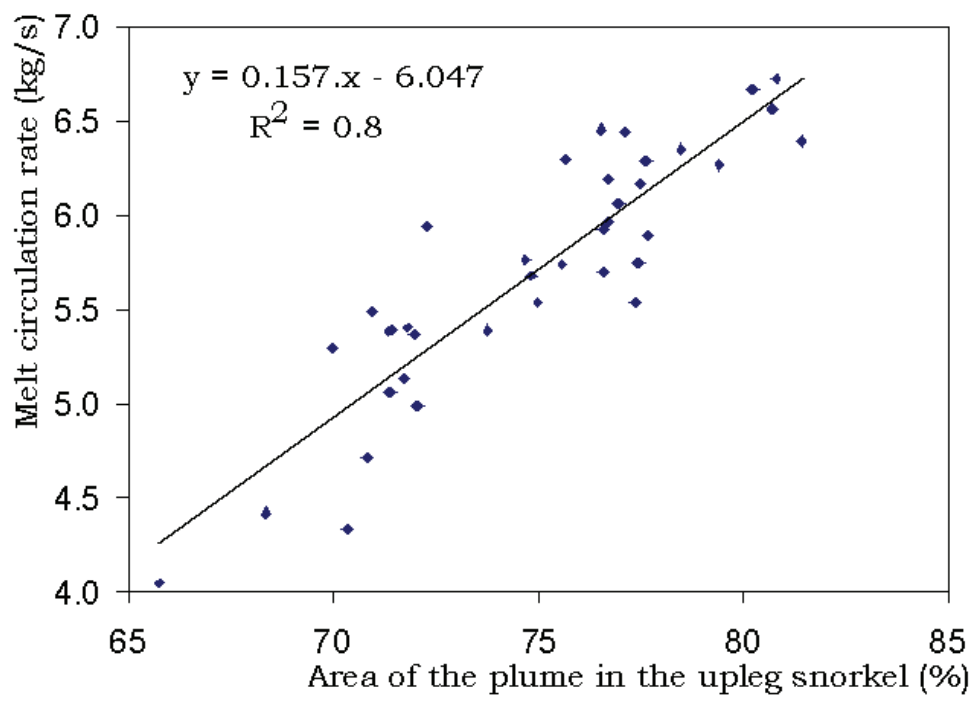

Fig. 7. Variation of the melt circulation rate with the plume area in the upleg snorkel

This parameter was correlated to the modified Froude number defined as

$$
\mathrm{Fr}_{\mathrm{m}}=\frac{\rho_{\mathrm{g}} \mathrm{Q}^{2}}{\mathrm{~d}_{\mathrm{o}}^{5} \mathrm{~g}\left(\rho_{1}-\rho_{\mathrm{g}}\right)}
$$

where

$\rho_{\mathrm{g}}$ is the density of the gas injected (air) $\left(\mathrm{kg} / \mathrm{m}^{3}\right)$,

$\mathrm{Q}$ is volumetric flow rate of the gas injected in the upleg snorkel $\left(\mathrm{m}^{3} / \mathrm{s}\right)$, $\rho_{l}$ is the density of the liquid (water) $\left(\mathrm{kg} / \mathrm{m}^{3}\right)$.

The results for different nozzles are presented in Fig. 8. It can be seen that there is a logarithmic relationship between the two parameters and that one single equation fit the results for the different nozzles. The relation between these two dimensionless numbers is reasonable, since the modified Froude number is related to the geometry of the plume formed in the upleg snorkel (Sato et al, 2004).

\subsubsection{Decarburization rate}

In the model proposed by Yamaguchi et al (1992), the variation of the concentration of aqueous $\mathrm{CO}_{2}$ (shown in Fig. 3) can be expressed by a first order reaction rate given by

$$
-\frac{\mathrm{dCO}_{2_{\mathrm{aq}}}}{\mathrm{dt}}=\mathrm{K}\left(\mathrm{C}_{\mathrm{CO}_{2 \mathrm{aq}}}-\mathrm{C}_{\mathrm{CO}_{2 \mathrm{aq}}}^{\mathrm{eq}}\right)
$$

where

$\mathrm{C}_{\mathrm{CO}_{2 a q}}$ is the concentration of aqueous $\mathrm{CO}_{2}$ in the ladle $(\mathrm{mg} / \mathrm{l})$,

$\mathrm{t}$ is the time (s),

$\mathrm{K}$ is the reaction constant $\left(\mathrm{s}^{-1}\right)$,

$\mathrm{Ceq}_{\mathrm{CO}_{2 a q}}$ is the concentration of aqueous $\mathrm{CO}_{2}$ in equilibrium with the gas phase. 
In this model, the rate constant is given by

$$
\mathrm{K}=\frac{1}{\mathrm{~W}\left(\frac{1}{\Gamma}+\frac{1}{\mathrm{ak}_{\mathrm{c}} \rho}\right)}
$$

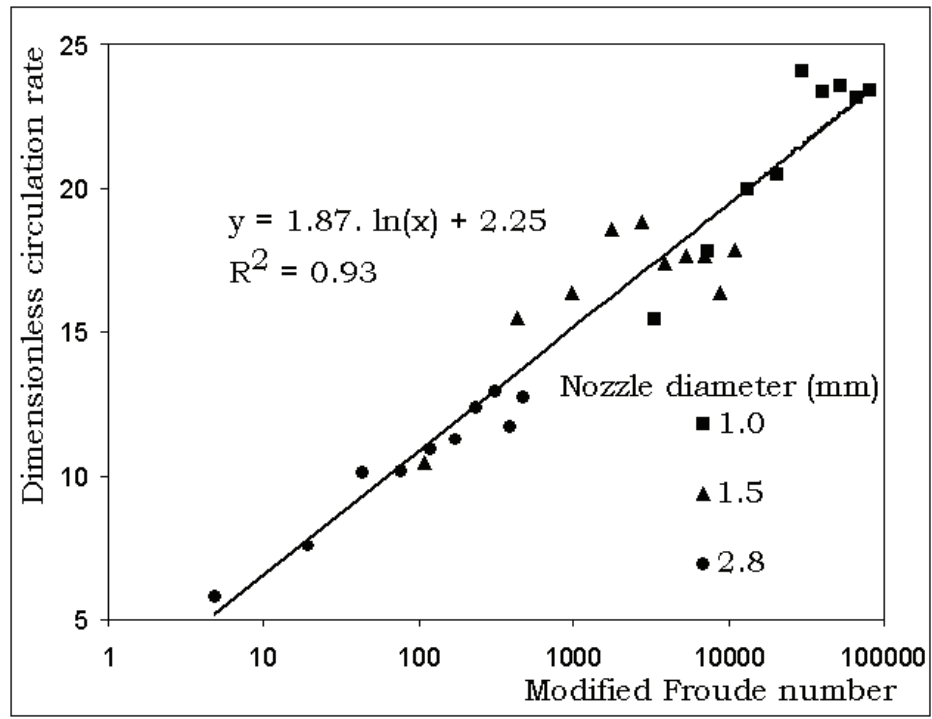

Fig. 8. Relation between the dimensionless circulation rate and the modified Froude number where

$\mathrm{W}$ is the mass of water in the ladle $(\mathrm{kg})$,

$\Gamma$ is the circulation rate $(\mathrm{kg} / \mathrm{s})$,

a is the reaction area $\left(\mathrm{m}^{2}\right)$,

$\mathrm{k}_{\mathrm{c}}$ is the mass transfer coefficient $(\mathrm{m} / \mathrm{s})$,

$\rho$ is the density of water $\left(\mathrm{kg} / \mathrm{m}^{3}\right)$.

The following assumptions were made in the development of this model:

- the reaction rate is controlled by mass transfer in the liquid,

- $\quad$ the liquid is perfectly mixed in the ladle and in the vacuum chamber and

- the amount of liquid in the ladle is much larger than that in the vacuum chamber.

All these assumptions seem very reasonable in the present investigation.

Equation (8) can be integrated to give

$$
-\ln \frac{\left(\mathrm{C}_{\mathrm{CO}_{2 \mathrm{aq}}}-\mathrm{C}_{\mathrm{CO}_{2 \mathrm{aq}}}^{\mathrm{eq}}\right)}{\left(\mathrm{C}_{\mathrm{CO}_{2 \mathrm{aq}}}^{\mathrm{i}}-\mathrm{C}_{\mathrm{CO}_{2 \mathrm{aq}}}^{\mathrm{eq}}\right)}=\mathrm{kt}
$$

where $\mathrm{C}^{\mathrm{i}} \mathrm{CO}_{2 \mathrm{aq}}$ is the initial concentration of aqueous $\mathrm{CO}_{2}$. 
A plot of the experimental data is presented in Fig. 9. This graph indicates that the results are very well reproduced by equation (10). The value of $\mathrm{K}$ is given by the slope of the straight line.

The product a. $\mathrm{k}_{\mathrm{c}}$ can be estimated using equation (9). This product represents the volumetric mass transfer coefficient.

Fig. 10 presents the variation of the logarithm of the volumetric mass the transfer coefficient as a function of the logarithm of the gas flow rate (Q). Sakaguchi and Ito(15) also calculated the volumetric mass transfer coefficient for gas stirred vessels under reduced pressure. They expressed the mass transfer coefficient as a function of the gas flow rate. According to their analysis, the mass transfer coefficient was expected to be proportional to the 0.744 power of the gas flow rate (although their experimental results indicated a power of 0.717 ), when the vacuum chamber pressure and the temperature are constant. The straight line with a slope of 0.744 is also indicated in figure 10 .

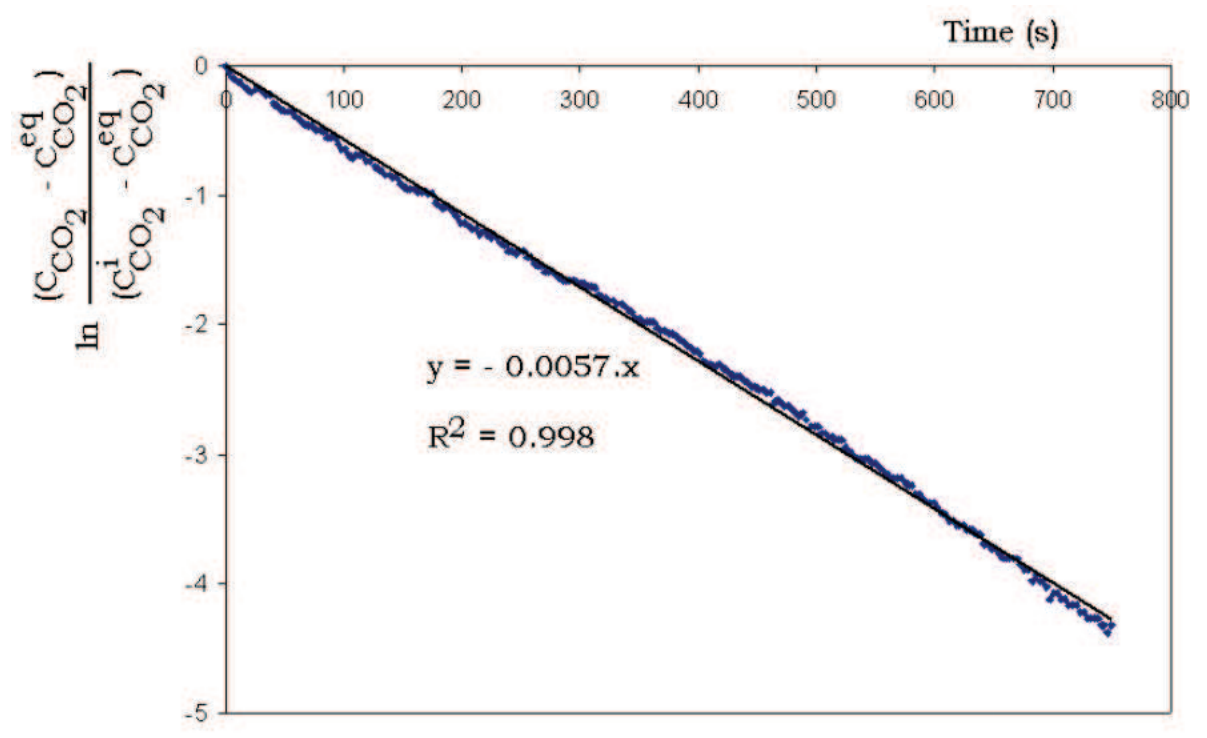

Fig. 9. Experimental data plot according to equation (10)

In the region of low flow rates, the slopes of the curves are similar to that indicated by Sakaguchi \& Ito (1995). At higher flow rates, particularly for the nozzles with diameters of 1.5 and $2.8 \mathrm{~mm}$, there is an increase in the slope above a certain flow rate. The behavior observed in Fig. 10 can be analyzed considering that there are two sites for the reaction to occur. One is in the interface between the gas and the liquid in the upleg snorkel. The other site is in the vacuum chamber and is usually associated to the splash that occurs there. In their study, Sakaguchi \& Ito (1995) admitted that the contribution of the mass transfer at the free surface could be neglected. Apparently, the slope of 0.744 is valid for situations where the contribution of the mass transfer at the free surface is small. When this contribution is more significant, i.e. when the splash in the vacuum chamber is more pronounced, there is a tendency of the slope to increase. This is probably the cause of the increase in the slope observed in Fig. 10, especially for nozzle diameters of 1.5 and $2.8 \mathrm{~mm}$. 


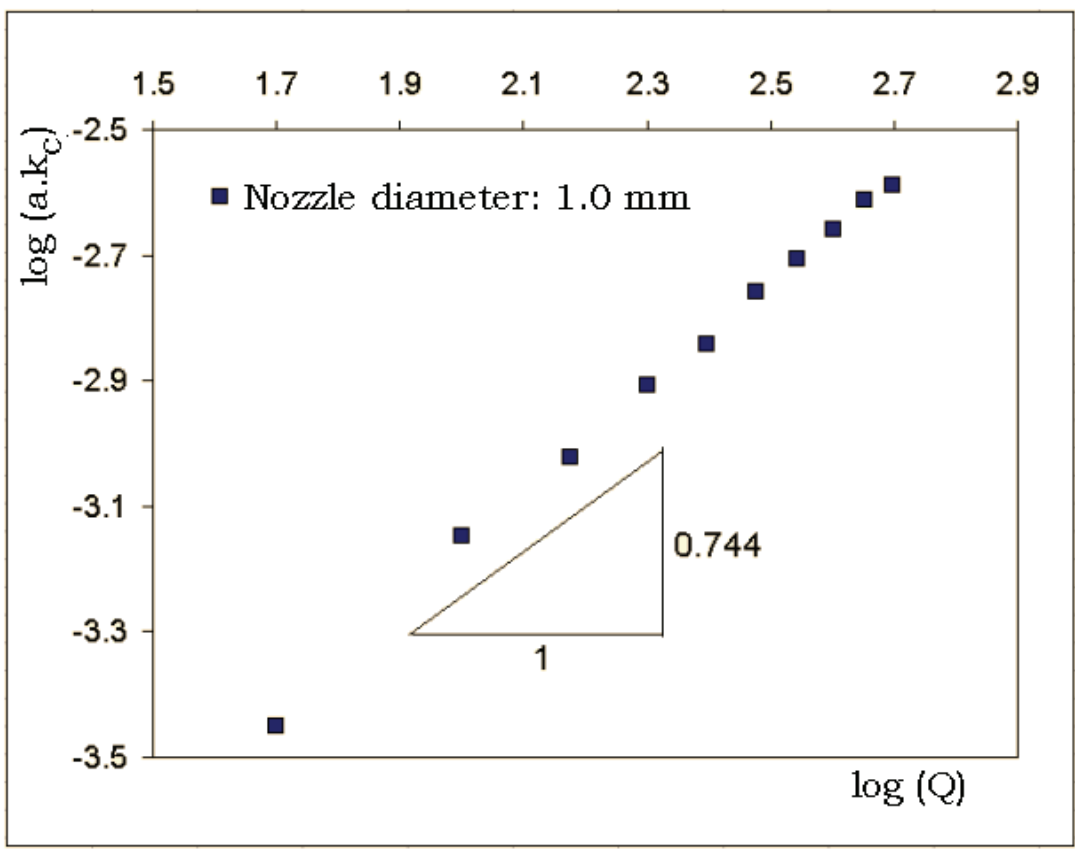

a) Nozzle diameter: $1.0 \mathrm{~mm}$

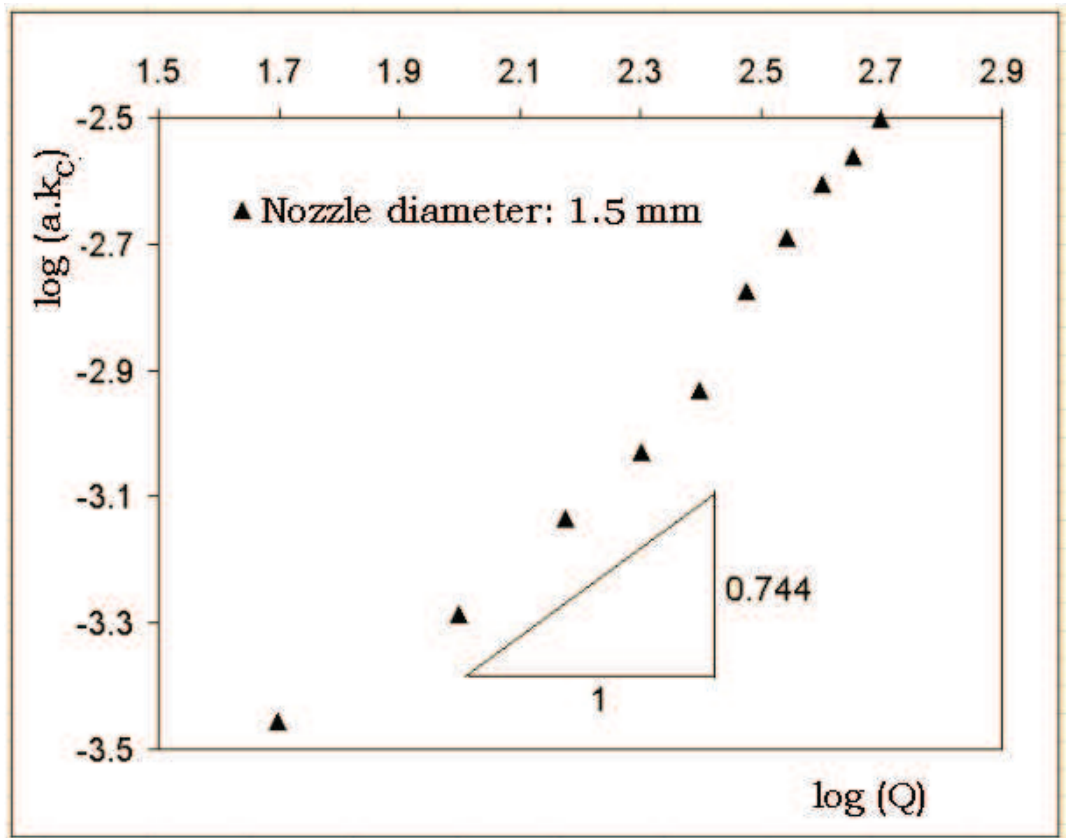

b) Nozzle diameter: $1.5 \mathrm{~mm}$ 


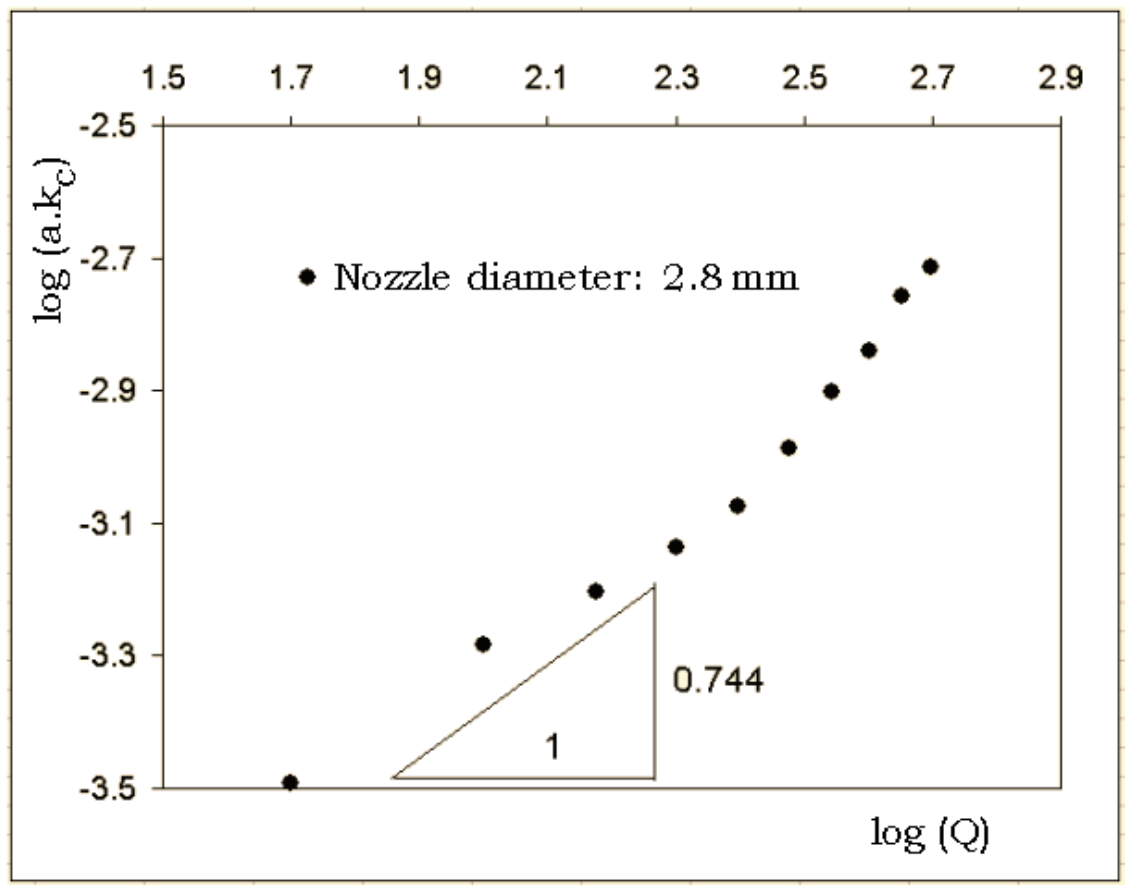

c) Nozzle diameter: $2.8 \mathrm{~mm}$

Fig. 10. Relation between the gas flow rate and the volumetric mass transfer coefficient for the three nozzle diameters

In a previous work developed with a copper converter, Themelis \& Schmidt (1967) related the volumetric mass transfer coefficient to the nozzle Reynolds number. They determined a linear relationship between the mass transfer coefficient and the Reynolds number in the range of 2,000 to 9,000. The same straight line fit the results for different nozzle diameters.

Fig. 11 shows the values of the mass transfer coefficient as a function of the nozzle Reynolds number obtained in the present work. In the low Reynolds region $(\operatorname{Re}<15,000)$, the effect of the nozzle diameter is relatively small and the results indicate a linear relationship between the mass transfer coefficient and the Reynolds number. For Reynolds number above 15,000, the linear trend remains, but the slopes of the lines for the different nozzles increase. The magnitude of this increase varies according to the nozzle diameter. For the $1.0 \mathrm{~mm}$ nozzle, the variation is very small. For the other two nozzles, the variation is more noticeable.

The behavior observed in Fig. 11 can also be analyzed considering the two reaction sites. The relevance of each site changes according to the Reynolds number and to the nozzle diameter. For the $1.0 \mathrm{~mm}$ nozzle, the jet coming from the nozzle disrupts in very small bubbles, with large surface area. In this case, the site in the upleg snorkel has a significant role even when the splash in the vacuum chamber is pronounced. For the nozzles with bigger diameters, particularly for those with $2.8 \mathrm{~mm}$ diameter, the effect of the splash becomes more relevant at higher Reynolds number, especially when a swinging motion of the bath surface is observed (Sato et al, 2004). This effect is probably responsible for the increase in the slopes of the lines observed in Fig. 11. 


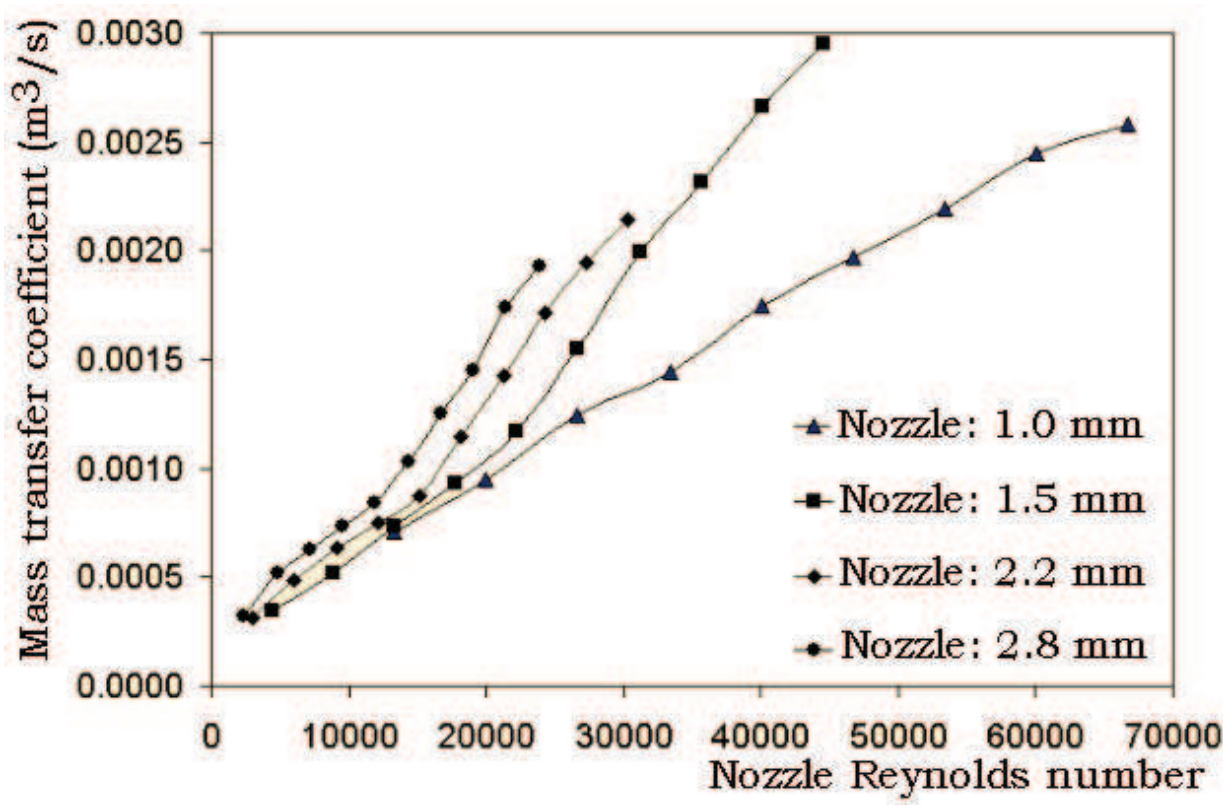

Fig. 11. Volumetric mass transfer coefficient as a function of the nozzle Reynolds number

Fig. 12 depicts images of the vacuum chamber, when different nozzles are used. The nozzle Reynolds number is approximately the same in three pictures. The splash is more pronounced for the $2.8 \mathrm{~mm}$ nozzle diameter and is certainly leading to the higher volumetric mass transfer coefficients observed in Fig. 11.

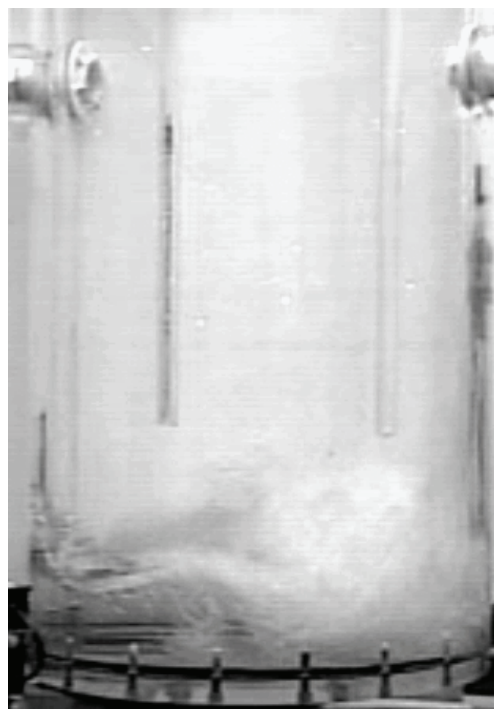

a) Nozzle: $1.0 \mathrm{~mm}$ 


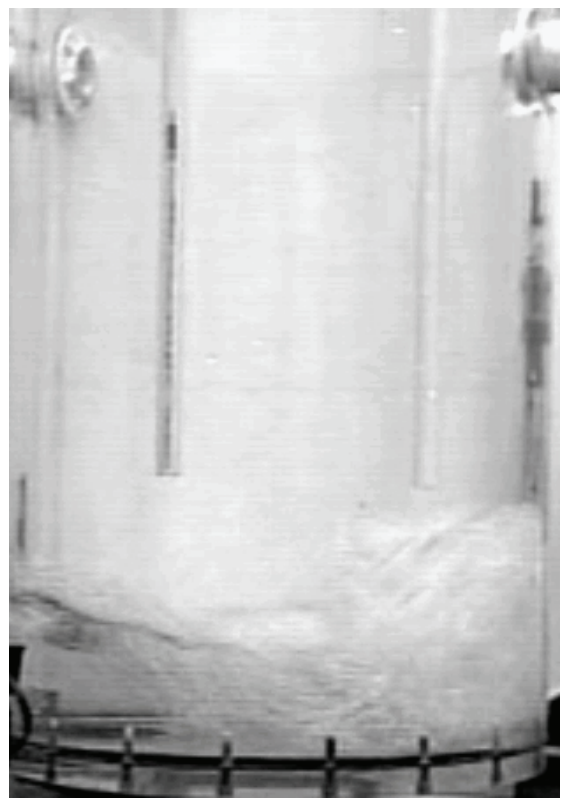

b) Nozzle: $1.5 \mathrm{~mm}$

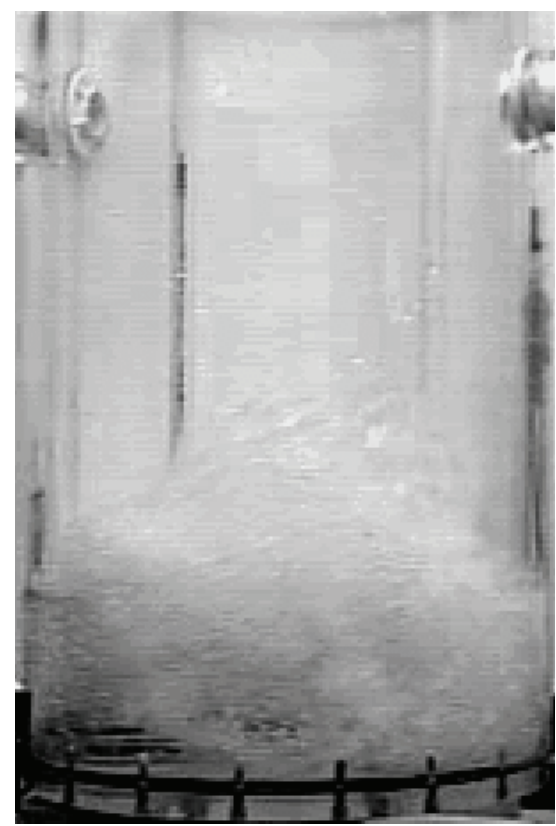

c) Nozzle: $2.8 \mathrm{~mm}$.

Fig. 12. Images of the vacuum chamber when different nozzles are used. Nozzle Reynolds number $\cong 20,000$ 


\section{Conclusions}

Mass transfer plays a significant role in determining the rate of steelmaking operations. Therefore, the evaluation of the mass transfer coefficient and the identification of the factors that affect the mass transfer rate are very important tasks. After defining the mass transfer coefficients and briefly discussing the techniques applied in their evaluation, a case study, analysing decarburization in the RH degasser was presented.

In this case study, a physical model was used to study the circulation rate and the kinetics of decarburization in a RH degasser. The effects of the gas flow rate and of the diameters of the nozzles used in the gas injection were investigated. The decarburization of liquid steel was simulated using a reaction of desorption of $\mathrm{CO}_{2}$ from caustic solutions.

The results showed that the circulation rate increases with an increase in the diameter of the nozzles and in the gas flow rate. The effect of the gas flow rate becomes less significant at higher flow rates. A relationship between a dimensionless circulation rate and the modified Froude number was determined. This relationship fit the results for all nozzle diameters tested.

The kinetics of the reaction follows a first order equation and is controlled by mass transfer in the liquid phase. The reaction rate constant was affected by the gas flow rate and nozzle diameter. An increase in the gas flow rate lead to an acceleration of the reaction. For a given flow rate, the smaller nozzle tend to give higher reaction rates.

A volumetric mass transfer coefficient was calculated based on the rate constants and on the circulation rate. The logarithm of the mass transfer coefficient showed a linear relationship with the logarithm of the gas flow rate. The slope of the line was found to vary according to the relevance of the reaction at the free surface in the vacuum chamber.

A linear relationship between the volumetric mass transfer coefficient and the nozzle Reynolds number was also observed. Again, the slopes of the lines changed according to the relative importance of the two reaction sites, gas-liquid interface in the upleg snorkel and in the vacuum chamber (mainly due to the splash). At higher Reynolds number, the reaction in the vacuum chamber tends to be more significant.

\section{Acknowledgments}

The financial support of FAPEMIG in the form of a research grant to R. P. Tavares (Process No. TEC - PPM-00197-09) is gratefully acknowledged.

\section{References}

Guo, D. \& Irons, G.A. (1998). Water Modeling of Vacuum Decarburization in a Ladle, Proceedings of the 1998 Steelmaking Conference Proceedings, pp. 601-607, 1886362-26-2.

Hamano, T.; Horibe, M. \& Ito, K. (2004). The Dissolution Rate of Solid Lime into Molten Slag Used for Hot-metal Dephosphorization. ISIJ International, 44, 2, 263-267, 0915-1559.

Inoue, S.; Furuno, Y.; Usui, T. \& Miyahara, S. (1992). Acceleration of Decarburization in RH Vacuum Degassing Process, ISIJ International, 32, 1, 120-125, 0915-1559.

Kamata, C.; Matsumura, H; Miyasaka, H.; Hayashi, S.; Ito, K. (1998). Cold Model Experiments on the Circulation Flow in RH Reactor Using a Laser Doppler Velocimeter, Proceedings of the 1998 Steelmaking Conference, (1998), pp. 609-616, 1-886362-26-2. 
Kishimoto, Y.; Yamaguchi, K.; Sakuraya, T. \& Fujii, T. (1993). Decarburization Reaction in Ultra-Low Carbon Iron Melt Under Reduced Pressure, ISIJ International, 33, 3, 391 399, 0915-1559.

Kitamura, S-Y; Miyamoto, K.I.; Shibata, H.; Maruoka, N. \& Matsuo, M. (2009). Analysis of Dephosphorization Reaction Using a Simulation Model of Hot Metal Dephosphorization by Multiphase Slag. ISIJ International, 49, 9, 1333-1339, 09151559.

Kondo, H.; Kameyama, K; Nishikawa, H.; Hamagami, K. \& Fujji, T. (1989). Comprehensive refining process by the Q-BOP-RH Route for Production of Ultra-Low Carbon Steel, Iron \& Steelmaker, 16, 10, 34-38.

Kuwabara, T.; Umezawa, K; Mori, K \& Watanabe, H. (1988). Investigation of Decarburization Behavior in RH-Reactor and its Operation Improvement, Transactions of ISIJ, 28, 4, 305-314, 0021-1583.

Maruoka, N.; Lazuardi, F.; Nogami, H.; Gupta, G.S. \& Kitamura, S-Y. (2010) Effect of Bottom Bubbling Conditions on Surface Reaction Rate in Oxygen-Water System. ISIJ International, 50, 1, 89 -94, 0915-1559

Nakanishi, K.; Szekely, J. \& Chang, C.W. (1975). Experimental and Theoretical Investigation of Mixing Phenomena in the RH-Vacuum Process, Ironmaking \& Steelmaking, 2, 2, 115-124, 0301-9233.

Park, Y-G.; Yi, K-W \& Ahn, S-B. (2001). The Effect of Operating Parameters and Dimensions of the RH System on Melt Circulation Using Numerical Calculations, ISIJ International, 41, 5, 403-409, 0915-1559.

Park, Y-G.; Doo, W-C; Yi, K-W \& Ahn, S-B. (2000). Numerical Calculation of Circulation Flow Rate in the Degassing Rheinstahl-Heraeus Process, ISIJ International, 40, 8, 749-755, 0915-1559.

Sakaguchi, K. \& Ito, K. (1995). Measurement of the Volumetric Mass Transfer Coefficient of Gas-Stirred Vessel under Reduced Pressure, ISIJ International, 35, 11, 1348-1353, 0915-1559.

Sato, T.; Bjurström, M.; Jönsson, P. \& Iguchi, M. (2004). Swinging Motion of Bath Surface Induced by Side Gas Injection, ISIJ International, 44, 11, 1787-1792, 0915-1559.

Seshadri, V. Costa, S.L.S. (1986). Cold Model Studies of RH Degassing Process, Transactions of ISIJ, 26, 2, 133-138, 0021-1583.

Seshadri, V.; Silva, C.A.; Silva, I.A.; Vargas, G.A. \& Lascosqui, P.S.B. (2006). Decarburization Rates in RH-KTB Degasser of the CST Steel Plant (Companhia Siderúrgica de Tubarão, Vitória, Brazil) Through a Physical Modeling Study, Ironmaking \& Steelmaking, 33, 1, 34-38, 0301-9233.

Singh, V.; Lenka, S.N.; Ajmani, S.K.; Bhanu, C. \& Pathak, S. (2009). A Novel Bottom Stirring Scheme to Improve BOF Performance through Mixing and Mass Transfer Modelling. ISIJ International, 49, 12, 1889-1894, 0915-1559

Takahashi, M.; Matsumoto, H. \& Saito, T. (1995). Mechanism of Decarburization in RH Degasser, ISIJ International, 35, 12, 1452-1458, 0915-1559.

Themelis, N.J. \& Schmidt, P.R. (1967). Transactions of AIME, 239 , 1313, ISSN.

Wei, J-H; Jiang, X-Y.; Wen, L-J. \& Li, B. (2007). Mass Transfer Characteristics between Molten Steel and Particles under Conditions of RH-PB(IJ) Refining Process. ISIJ International, 47, 3, 408-417, 0915-1559.

Yamaguchi, K.; Kishimoto, Y.; Sakuraya, T.; Fujii, T.; Aratani, M. \& Nishikawa, H. (1992). Effect of Refining Conditions for Ultra Low Carbon Steel on Decarburization Reaction in RH Degasser, ISIJ International, 32, 1, 126-135, 0915-1559. 


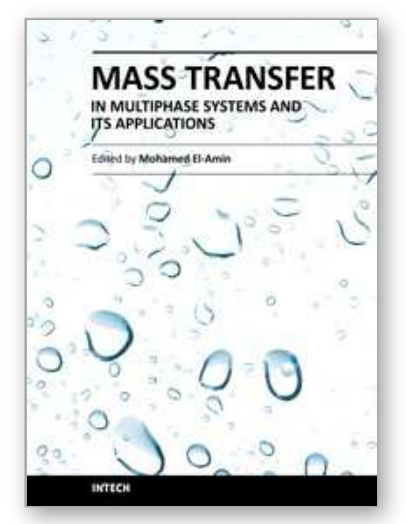

\author{
Mass Transfer in Multiphase Systems and its Applications \\ Edited by Prof. Mohamed El-Amin
}

ISBN 978-953-307-215-9

Hard cover, 780 pages

Publisher InTech

Published online 11, February, 2011

Published in print edition February, 2011

This book covers a number of developing topics in mass transfer processes in multiphase systems for a variety of applications. The book effectively blends theoretical, numerical, modeling and experimental aspects of mass transfer in multiphase systems that are usually encountered in many research areas such as chemical, reactor, environmental and petroleum engineering. From biological and chemical reactors to paper and wood industry and all the way to thin film, the 31 chapters of this book serve as an important reference for any researcher or engineer working in the field of mass transfer and related topics.

\title{
How to reference
}

In order to correctly reference this scholarly work, feel free to copy and paste the following:

Roberto Parreiras Tavares (2011). Mass Transfer in Steelmaking Operations, Mass Transfer in Multiphase Systems and its Applications, Prof. Mohamed El-Amin (Ed.), ISBN: 978-953-307-215-9, InTech, Available from: http://www.intechopen.com/books/mass-transfer-in-multiphase-systems-and-its-applications/mass-transfer-insteelmaking-operations

\section{INTECH}

open science | open minds

\section{InTech Europe}

University Campus STeP Ri

Slavka Krautzeka 83/A

51000 Rijeka, Croatia

Phone: +385 (51) 770447

Fax: +385 (51) 686166

www.intechopen.com

\section{InTech China}

Unit 405, Office Block, Hotel Equatorial Shanghai

No.65, Yan An Road (West), Shanghai, 200040, China

中国上海市延安西路65号上海国际贵都大饭店办公楼 405 单元

Phone: +86-21-62489820

Fax: +86-21-62489821 
(C) 2011 The Author(s). Licensee IntechOpen. This chapter is distributed under the terms of the Creative Commons Attribution-NonCommercialShareAlike-3.0 License, which permits use, distribution and reproduction for non-commercial purposes, provided the original is properly cited and derivative works building on this content are distributed under the same license. 